\title{
The Meat in the Sandwich: Welfare Labelling and the Governance of Meat Chicken Production in Australia
}

\author{
CHRISTINE PARKER*, RACHEL CAREY**, GYORGY SCRINIS*** \\ Journal of Law and Society, 2018, 45(3), 341-369
}

\begin{abstract}
This paper critically examines the degree to which higher animal welfare label claims change animal welfare regulation and governance within intense meat chicken ("broiler") production in Australia. The paper argues that ethical labelling claims on food and other products can be seen as a "governance space' in which various government, industry and civil society actors compete and collaborate for regulatory impact. It concludes that ethical labelling can act as a pathway for re-embedding social concerns in the market, but only when it prompts changes that become enshrined in standard practice and possibly the law itself. Moreover, the changes wrought by ethical labelling are small and incremental. Nevertheless, labelling may create ongoing productive tension and "overflow" that challenges the market to listen to and accommodate actors (including animals) on the margins to create ongoing incremental changes.
\end{abstract}

* Melbourne Law School, University of Melbourne, VIC 3010, Australia christine.parker@unimelb.edu.au

**Faculty of Veterinary and Agricultural Sciences, University of Melbourne, VIC 3010,

Australia

rachel.carey@unimelb.edu.au

***School of Agriculture and Food, Faculty of Veterinary and Agricultural Sciences,

University of Melbourne, VIC 3010, Australia

gyorgys@unimelb.edu.au

The authors are grateful to the stakeholders interviewed for this research and Josephine De Costa, Geordie Fung, Joe Lasco, Adaena Sinclair-Blakemore, Zoe Jackson and Laura Boehm for assistance in fieldwork and manuscript preparation. This research was funded by Australian Research Council Discovery Project DP150102168, "Regulating Food Labels: The Case of Free Range Food Products in Australia". 


\section{INTRODUCTION}

Many consumers mistakenly believe that meat chickens are raised in cages and administered hormones. ${ }^{1}$ While this is not the case, the conditions in which chickens (or "broilers") are raised and slaughtered are far from ideal. They are housed in minutely controlled conditions at high densities in very large barns to create the maximum amount of meat in the shortest possible time. ${ }^{2}$ In response to public concern about the way chickens and other animals are treated, marketing terms, such as "free range", "RSPCA Approved", "certified humane", and "animal welfare assured" have emerged in Australia and other countries. ${ }^{3}$ This paper critically evaluates whether these label claims make any difference to industry practice and animal welfare governance.

The first part of the paper suggests that food labelling can be seen as a "governance space" in which labelling initiatives could help facilitate contestation and change in markets. This type of "political" consumerism would however require both accurate labelling and interaction between label claims and a governance network of industry, retail, government and civil society actors behind the label.

The second part of the paper sets out the context of rapidly expanding intense industrial chicken meat production and consumption in Australia, and the methodology of "backwards mapping" the network of governance behind label claims.

The third part of the paper critically examines the accuracy of the two dominant higher welfare label terms in Australia (FREPA free range and RSPCA Approved), and whether and to what degree they change the governance and practice of meat chicken welfare. We conclude that the widespread adoption of RSPCA Approved certification and labelling has probably led to small incremental improvements in the welfare of the majority of meat chickens in Australia. This is because RSPCA Approved has slightly higher welfare standards and better monitoring and enforcement practices than government regulation and industry self-regulation. FREPA free range, by contrast, does not guarantee that chickens are actually free range, does not guarantee higher welfare standards are actually met and applies to only a minority of chickens (about 15 per cent). Neither label challenges the fundamentals of a system that is largely aimed at producing more and more chicken meat more and more efficiently to meet retailer and consumer demand for inexpensive and abundant meat, at the expense of the chickens themselves, who are the 'meat in the sandwich'.

The fourth part of the paper concludes that any welfare improvements for meat chickens through labelling alone are a "fragile construction", 4 dependent on a particular confluence of retailer, consumer and social movement advocacy at a particular time. Nevertheless, ongoing consumer and social movement contestation of free range and higher welfare label claims is creating ongoing productive tension and "overflow" that may challenge market actors to listen to and accommodate actors on the margin. ${ }^{5}$ Thus labelling can have some catalyzing role in changing governance and practice in the food system.

\footnotetext{
${ }^{1}$ See V. Kite, 'The Hormone Myth', at <http://www.chicken.org.au/chookchat/the-hormone-myth/>.

${ }^{2}$ See nn. 42 to 69 below and accompanying text.

${ }^{3}$ Observations from our own product surveys in Australia, United Kingdom and United States (discussed below).

${ }^{4}$ M. Miele and J. Lever, 'Civilizing the Market for Welfare Friendly Products in Europe? The Techno-Ethics of the Welfare Quality ${ }^{\circledR}$ Assessment' (2013) 48 Geoforum 63, at 70.

${ }^{5}$ See nn. 6 to 9 below and accompanying text.
} 


\section{EVALUATING THE LABEL AS GOVERNANCE SPACE}

\section{The Promise of Labelling}

The trend towards animal welfare labelling of meat products is just one example of a broader consumer and citizen activist concern to address the many costs and externalities of markets. ${ }^{6}$ Michel Callon comments that markets constantly seek to frame certain actors, relationships and considerations as relevant to particular transactions and exclude others, yet there are always relations that "defy framing" and it is impossible to eliminate all "overflow". 7 Thus a 'good' market, one that works well, "is a market which welcomes and recognizes as one of its most central constituent elements all the actors who demand to be taken into account, including those who are considered as marginal..., with their points of view, their matters of concern, their proposed tools, framings and models." "Callon sees this as providing a normative opportunity to dynamically voice the tensions and concerns of actors and externalities impacted by markets, which will in turn reconfigure markets and our very ideas of politics and economy. ${ }^{9}$

Regulatory studies also proposes that both public and private actors can find opportunities to participate in networks of governance that regulate business and government practice - thus opening up business regulation to new voices and tools. ${ }^{10}$ David Levi-Faur's theory of regulatory capitalism observes that there is a constant and dynamic process of regulation, deregulation, re-regulation through interaction and contestation of regulation by market, state and civil society actors. ${ }^{11}$ Moreover this is not just a matter of state-centric regulation. Rather the contestation and regulation of the market occurs through a network of public and private actors who each regulate and are regulated by one another at different times. ${ }^{12}$ Thus private governance standards including industry or NGO labelling and certification schemes, supermarket supply standards, and activist publicity campaigns can all be seen as elements of regulatory governance designed to re-embed the market in the social.

The retail label is one of the most visible and accessible spaces in which citizen-consumers can engage with the networks of public and private actors that govern chains of food production and distribution. It is the mechanism by which the governance systems further back the chain behind the label are displayed, and a mechanism by which citizen-consumers may seek to interpolate their views and values back into the governance of that system. ${ }^{13}$ Label claims may provide a mechanism for social and political contestation of the market in two ways:

\footnotetext{
${ }^{6}$ F. Block, 'Karl Polyani and the Writing of The Great Transformation' (2003) 32 Theory and Society 275; J. Guthman, 'The Polanyian Way? Voluntary Food Labels as Neoliberal Governance' (2007) 39 Antipode 456.

${ }^{7}$ M. Callon, 'Introduction: The Embeddedness of Economic Markets in Economics' in The Laws of the Markets, ed. M. Callon (1998) 17-18.

${ }^{8}$ M. Callon, 'Civilizing Markets: Carbon Trading between in Vitro and in Vivo Experiments' (2009) 34

Accounting, Organisations and Society 535, at 541.

${ }^{9}$ id., p. 544.

${ }^{10}$ J. Braithwaite and P. Drahos, Global Business Regulation (2000).

${ }^{11}$ D. Levi-Faur, 'Regulatory Capitalism' in Regulatory Theory: Foundations and Applications, ed. P. Drahos (2017).

${ }^{12}$ K. Abbott and D. Snidal, 'The Governance Triangle: Regulatory Standards Institutions and the Shadow of the State' in The Politics of Global Regulation, eds. W. Mattli and N. Woods (2009) 44-88; B. Eberlein et al., 'Transnational Business Governance Interactions: Conceptualization and Framework for Analysis' (2014) 8 Regulation \& Governance 1.

${ }^{13}$ See R. Carey, C. Parker and G. Scrinis, 'Capturing the Meaning of "Free Range": The Contest between Producers, Supermarkets and Consumers for the Higher Welfare Egg Label in Australia' (2017) 54 J. of Rural Studies 266; C. Parker, 'The Food Label as Governance Space: Free Range Eggs and the Fallacy of Consumer Choice' (2014) 35 Recht der Werkelijkheid 101.
} 
First label claims can invite consumers to express alternative social values and ideals of a good life to those offered elsewhere in the market. ${ }^{14}$ This may take various forms - from halal or kosher certification, to fair trade, environmental and animal welfare values. It also allows food producers and retailers to increase profit margins via market niche differentiation and quality labelling. ${ }^{15}$ However, as discussed below, these label claims are also vulnerable to exploitation, misinterpretation and misleading or partial representations of reality.

Second, labelling can become a mechanism for exerting political influence over the market to change production practices by enabling civil society organisations to advocate for consumers to "buycott" some goods and boycott others (choose which goods to buy or not buy on the basis of qualities of the goods). This goes beyond consuming with meaning (as in the first conception above) to "shopping for change" - advocating for alternative mechanisms to govern industry practice such as different business to business requirements (supermarket supply standards), and labelling and certification standards (production and process standards). ${ }^{16}$

\section{Critical Analysis of Labelling as a Governance Space}

In order to assess the degree to which labelling claims make a difference to the governance of the food system, this paper examines higher welfare labelling on meat chicken products in Australia, and asks two critical questions:

- Do label claims accurately inform consumer choice?

- Does the interaction of regulatory actors behind the label, the higher welfare claims on the label, and consumer choices prompt change in production practices and their regulation and governance in relation to animal welfare?

(a) Do label claims accurately inform consumer choice?

The first question asks whether higher welfare claims mislead consumers and civil society thus negating the opportunity for influence. Survey evidence (from 2007) suggests that "the majority of Australians see industrialised and intensive farming practices as both unnatural and antithetical to animal welfare". ${ }^{17}$ About two thirds of Australians claim to have bought "free range" or "humane" meat or dairy products at some stage because of their concern for animals. ${ }^{18}$ Consumer research however suggests that citizen understanding and knowledge of meat production practices and welfare science in particular is generally very weak. ${ }^{19}$

\footnotetext{
${ }^{14}$ See M. Miele and A. Evans, 'When Foods Become Animals: Ruminations on Ethics and Responsibility in Care-Full Practices of Consumption' (2010) 13 Ethics, Place and Environment 171. See also S. Barr, A. Gilg and G. Shaw, 'Citizens, Consumers and Sustainability: (Re)Framing Environmental Practice in an Age of Climate Change' (2011) 21 Global Environmental Change 1224; L. Middlemiss, 'Reframing Individual Responsibility for Sustainable Consumption: Lessons from Environmental Justice and Ecological Citizenship' (2010) 19 Environmental Values 147.

${ }^{15}$ See T. Bartley et al., Looking Behind the Label: Global Industries and the Conscientious Consumer (2015); B. Ilbery et al., 'Product, Process and Place: An Examination of Food Marketing and Labelling Schemes in Europe and North America' (2005) 12 European Urban and Regional Studies 116.

${ }^{16}$ Cf. R.J. Roff, 'Shopping for Change? Neoliberalizing Activism and the Limits to Eating Non-GMO' (2007) 24 Agriculture and Human Values 511; D. Shaw and I. Black, 'Market Based Political Action: A Path to Sustainable Development?' (2010) 18 Sustainable Development 385.

${ }^{17}$ P. Chen, Animal Welfare in Australia: Politics and Policy (2016) 73.

18 id., p. 59.

${ }^{19}$ See I. Erian and C. Phillips, 'Public Understanding of and Attitudes Towards Meat Chicken Production and Relations to Consumption' (2017) 7 Animals 1; C. Hall and V. Sandilands, 'Public Attitudes to the Welfare of Broiler Chickens' (2007) 16 Animal Welfare 499.
} 
Contemporary consumers are distant from producers due to long supply chains, the market dominance of the supermarket and information asymmetry between consumers and producers. ${ }^{20}$ Australian consumers have relatively little knowledge of the conditions of chicken production, ${ }^{21}$ and may lump together or confuse issues of taste, naturalness (including use of additives and hormones), "organic", small scale, local and family farming with higher welfare and free range label terms. ${ }^{22}$ In the case of meat, consumers also tend to shy away from obtaining specific knowledge of where their food comes from, how the animal is treated, and even thoughts about the food coming from an animal at all. ${ }^{23}$ Retailers present animal food to consumers in a way that facilitates this distancing, for example by avoiding showing representations of the whole animal on the packaging, or showing only old fashioned bucolic scenes with rustic barns or cartoon or silhouette style animals. ${ }^{24}$

Consumers may be well intentioned but lack clear and practical ideas of what they want to see changed in intensive meat chicken production, and how much they are willing to give up (higher price, less meat) to do so. Producers and retailers are therefore in a good position to manipulate and take advantage of consumer desire for ethical products via "credence claims" that most consumers are not in a position to understand or check for themselves. The contemporary supermarket dominated food retail system also encourages the idea that quality is consistent with affordable prices and high availability. This is particularly evident in Australian and United Kingdom supermarket's adoption of ethical brand identities that include concern for animal welfare while maintaining low prices - thus selling the idea that both are possible at the same time. ${ }^{25}$

This heightens the possibility that higher animal welfare claims on food product labels may mislead consumers. Misleading conduct can be quite stark: products may be labelled one way, but actually fraudulently contain substitutes produced a different way (for example, cage eggs labelled "free range"). ${ }^{26}$ In this paper however we focus on a subtler type of misleading labelling. Label claims can construct difference by trumpeting small or cosmetic changes (for example, popholes out of barns to ranges that most birds do not actually access ${ }^{27}$ ) or highlighting and renaming production systems that are no different to the norm (for example, labelling intensive barn production "free to roam"). ${ }^{28}$ These small changes can "encompass", ${ }^{29}$ co-opt or create a "simulacram" of alternative methods of animal production, thus blurring the

\footnotetext{
${ }^{20}$ J. Clapp, Food (2012) 1; C. Richards, G. Lawrence and D. Burch, 'Supermarkets and Agro-Industrial Foods' (2011) 14 Food, Culture and Society 29.

${ }^{21}$ Erian and Phillips, op. cit., n. 19.

${ }^{22}$ See H.J. Bray and R.A. Ankeny, 'Happier Chickens Lay Tastier Eggs: Motivations for Buying Free-Range Eggs in Australia' (2017) 30 Anthrozoös 213; G.C. Harper and A. Makatouni, 'Consumer Perception of Organic Food Production and Farm Animal Welfare’ (2002) 104 Brit. Food J. 287.

${ }^{23}$ Erian and Phillips, op. cit., n. 19; M. Schröder and M. McEachern, 'Consumer Value Conflicts Surrounding Ethical Food Purchase Decisions: A Focus on Animal Welfare' (2004) 28 International J. of Consumer Studies 168.

${ }^{24}$ Chen, op. cit., n. 17, pp. 112-14. See, also, S. O'Sullivan, Animals, Equality and Democracy (2011) 64-70.

${ }^{25}$ See J. Dixon, The Changing Chicken: Chooks, Cooks and Culinary Culture (2002) 113.

${ }^{26}$ See J. Curll, 'The Significance of Food Fraud in Australia' (2015) 43 Aus. Business Law Rev. 270, at 280-1; Australian Competition and Consumer Commission v. CI \& Co Pty Ltd [2010] FCA 1511; Australian Competition and Consumer Commission v. Bruhn [2012] FCA 959.

${ }^{27}$ Australian Competition and Consumer Commission v. Pirovic Enterprises Pty Ltd (No. 2) [2014] FCA 1028.

${ }^{28}$ Australian Competition and Consumer Commission v. Turi Foods Pty Ltd (No. 2) [2012] FCA 19; Australian Competition and Consumer Commission v. Turi Foods Pty Ltd (No. 4) [2013] FCA 665.

${ }^{29}$ M. Fourcade and K. Healy, 'Moral Views of Market Society' (2007) 33 Annual Rev. of Sociology 285.
} 
boundaries between different production practices (for example, making intensive barn-based production appear more like smaller scale pasture-based production). ${ }^{30}$

(b) Do label claims prompt change?

This leads to the second question: do label claims prompt change? Higher welfare claims may not only mislead individual consumers about how differently individual products have been produced, but also give the (misleading) impression that shopping choices can "civilise" ${ }^{31}$ or regulate a whole market. ${ }^{32}$ Critical commentators have noted that issues like animal welfare represent collective public interests in which government regulation should set minimum standards. Labelling standards however merely create a market niche for those with sufficient knowledge and resources. ${ }^{33}$ This critique however underplays the dynamic, networked nature of contemporary regulatory capitalism. We suggest that it is possible, at least in principle, for ethical labelling initiatives to help change production practices by changing the network of governance actors. The questions are how much change and in what circumstances?

Regulatory network analysis draws attention to the way that the regulatory governance of any particular area at any particular time is the result of ongoing interactions (contests, conflicts, alliances, modelling and mimicry) by multiple actors (government, industry and civil society) at multiple levels (local, national and global) each seeking to exercise power legitimately and effectively. ${ }^{34}$ Regulatory network analysis suggests that markets are constituted by a set of changing relations in which public and private standards are continually being created, adjusted and solidified.

Investigation of the value chain that connects food production and consumption inevitably uncovers the importance of networks of public and private regulation and governance in sustaining and challenging food chains. ${ }^{35}$ Morgan, Marsden and Murdoch's seminal work on "worlds of food" for example shows that regulation - formal legal-contractual arrangements, logo accreditation schemes, legislative frameworks and informal conventions - are all integral to stabilising those chains and defining which values, interests and assumptions about how food production should be organised prevail in different links in the chains. ${ }^{36}$ Miele and Lever's study of the "techno-ethics" of high welfare meat chicken production in the EU argues that the emergence of ethically qualified products in the market requires constant work by actors in the supply chain to construct and sustain the market. This work includes convincing consumers to buy and trust certain label claims, updating the producers' own skills and technology (for example, barns designed appropriately to facilitate free ranging, managing chicken health under different conditions), and ensuring investment in new technologies and products (for example, retailers and brand-owners may need to assist growers with the capital to buy new barns). ${ }^{37}$ In order to evaluate the impact of label claims, then, we must inquire into not only

\footnotetext{
${ }^{30}$ Richards, Lawrence and Burch, op. cit., n. 20, p. 32.

${ }^{31}$ Callon, op. cit., n. 8.

${ }^{32}$ See Miele and Evans, op. cit., n.14. See, also, P. Fleming, The End of Corporate Social Responsibility: Crisis and Critique (2012) 13.

${ }^{33}$ Guthman, op. cit., n. 6.

${ }^{34}$ See references at n. 12 above. See, also, B. Cashore, G. Auld and S. Renckens, 'The Impact of Private, Industry and Transnational Civil Society Regulation and Their Interaction with Official Regulation' in Explaining Compliance: Business Responses to Regulation, eds. C. Parker and V.L. Nielsen (2011). 35 See, for example, J. Guthman, Agrarian Dreams: The Paradox of Organic Farming in California (2004) 11071.

${ }^{36}$ K. Morgan, T. Marsden and J. Murdoch, Worlds of Food: Place, Power and Provenance in the Food Chain (2006).

${ }^{37}$ Miele and Lever, op. cit., n. 4.
} 
the production practices behind certain label claims, but also whether they are adequately supported by robust technological and management changes in the supply chain, and ultimately the network of regulation that governs the supply chain.

Food labels can be a particularly important governance space to the extent that they provide not merely an opportunity for consumers to vote individually with their shopping dollar but to help change public and policy discourses, government regulation and industry governance to transform practice. Labelling does not automatically have this impact on networks of governance behind the label. Certain players in the value chain will have well established economic and discursive power over the way things are done. Supermarket supply contracts, for example, that require high availability and low cost will be very influential and hard to change. Moreover, civil society activists, including animal welfare advocates, are not the only "marginal" voices in the regulatory space competing for attention - family farmers, environmental advocates, food safety and bio security advocates all seek an influence too. Yet the dynamic, networked nature of governance provides opportunities for change, even if, as Miele and Lever suggest, the result is "more diffuse than specific" 38 - not wholesale changes in supply chains but contestation, problematizing and expansion of stakeholders and discourses in governance systems. Bartley and co-authors conclude from their study of the use of labelling in four different areas of global trade (pulp and paper, electronics, apparel and coffee) that "conscientious consumerism" (their term) "might be meaningful and progressive if treated as part of a repertoire of political engagement', 39 particularly where product labelling is used as an "entry point" for hard-headed engagement with policy issues. ${ }^{40}$ We suggest that it is in the very nature of regulatory capitalism that a range of industry and civil society actors will continually wish to contest market practices. In this context, label claims can provide opportunities to expand the relevant voices and interests in the governance of various industry practices. ${ }^{41}$ It is for researchers to map how they occur and for activists and entrepreneurs to find opportunities to make their voices heard.

\section{METHODOLOGY: BACKWARDS MAPPING HIGHER WELFARE LABELLING IN MEAT CHICKEN PRODUCTION IN AUSTRALIA}

\section{Growth in chicken meat consumption and production}

In western countries chicken meat consumption has grown exponentially in recent decades, with many consumers choosing chicken over beef and lamb. ${ }^{42}$ Australia is at the vanguard of this trend with a tenfold increase per capita since $1962^{43}$ and the third highest consumption per

\footnotetext{
38 id.

${ }^{39}$ Bartley et al., op. cit., n.15, p. 224.

40 id., p. 225.

${ }^{41}$ See, also, id., pp. 69-70; M. Micheletti, Political Virtue and Shopping: Individuals, Consumerism and Collective Action (2003).

${ }^{42}$ See M.J. Zuidhof et al., 'Growth, Efficiency, and Yield of Commercial Broilers from 1957, 1978 and 2005' (2014) 93 Poultry Sci. 2970, at 2970.

$434.4 \mathrm{~kg}$ per person per year in 1962; $47 \mathrm{~kg}$ in 2015-16: L. Wong, E.A. Selvanathan and S. Selvanathan, 'Changing Pattern of Meat Consumption in Australia' (2013) at $<$ https://www.murdoch.edu.au/School-ofBusiness-and-Governance/_document/Australian-Conference-of-Economists/Changing-pattern-of-meatconsumption-in-Australia.pdf>; Australian Bureau of Agricultural and Resource Economics and Sciences (ABARES), Agricultural Commodities: March Quarter 2017 (2017) 116, at <http://www.agriculture.gov.au/abares/Documents/agricultural-commodities-report-march-2017.pdf〉.
} 
capita in the world. ${ }^{44}$ Two supermarkets (Coles and Woolworths) dominate (60 per cent) the retail grocery market. ${ }^{45}$ Both now treat chicken meat as a staple commodity on a par with bread, milk and eggs: prices are lower than all other meats, ${ }^{46}$ availability high, and competition strong. ${ }^{47}$ Chicken also dominates fast food offerings, where it is available cheap and often fried! In Australia two large vertically integrated producers and processors dominate supply, controlling 75 per cent of the market. ${ }^{48}$ The integrated chicken producers either own or directly control each stage of production from the breeding and hatching of chicks, the milling and distribution of feed, provision of veterinary services, and the slaughter, processing, packing and often marketing of the final product. The actual growing of the chickens is usually however contracted out to growers. There are about 800 individual or family growers around Australia who grow the chickens to slaughter weight. Growers provide their own land and buy their own equipment (which must meet the producers' specifications), but the producers provide the feed and veterinary services and set the conditions under which the birds are housed, fed and managed. They also control the price at which the growers are paid.

These conditions of supermarket oligopoly and vertical integration of chicken production are typical of all western countries where consistent supply of inexpensive chicken meat has been achieved by innovation in the management and housing of the chickens indoors (including artificial lighting, water, and a suitable litter or ground substrate), improved nutrition (via a formulated grain-based diet), and, crucially, the selective breeding of the birds themselves to maximize the achievement of "commercially-important targets, especially efficient feed conversion and rapid growth rate". ${ }^{49}$ Between 1975 and 2005 meat chicken growth rates increased by over 400 per cent, but the amount of feed required approximately halved, 50 "with approximately $3 \mathrm{~kg}$ of feed producing a $2 \mathrm{~kg}$ meat chicken in 35 days [that is 5 weeks]". ${ }^{51}$ This means they are now a completely separate breed to layer hens. The birds are generally housed in very large, closed system industrial style sheds with thousands of other chickens. ${ }^{52}$ This system was characterized by animal activist Ruth Harrison as "factory farming" in which the animal itself is in many ways treated as a component in a meat-making machine. ${ }^{53}$ Certainly, as the next subsection shows, this large scale intense production system inherently produces a range of poor outcomes for chicken health, welfare and opportunity to engage in natural behaviours.

\section{Chicken health, welfare and opportunity to engage in natural behaviors}

David Fraser ${ }^{54}$ has influentially suggested that different stakeholders tend to focus on one or other of three different conceptions of animal welfare:

\footnotetext{
${ }^{44}$ Behind Israel and the US: OECD Data, 'Meat consumption', at $<$ https://data.oecd.org/agroutput/meatconsumption.htm>.

${ }^{45}$ Australian Competition and Consumer Commission (ACCC), Report of the ACCC Inquiry into the

Competitiveness of Retail Prices for Standard Groceries (2008).

${ }^{46}$ ABARES, op. cit., n. 43.

${ }^{47}$ Dixon, op. cit., n. 25, p. 113.

${ }^{48}$ Baiada and Inghams. Several other large companies also operate: Hazeldenes, Bartter, Turi Foods (La Ionica), Milne, Inglewood, and Milawa.

${ }^{49}$ A. Robins and C.J.C. Phillips, 'International Approaches to the Welfare of Meat Chickens' (2011) 67 World's Poultry Sci. J. 351, at 352 (references omitted). See, also, Zuidhof et al., op. cit., n. 42, p. 2971; H.A. Elson et al., 'Poultry Welfare Management: WPSA Working Group Nine' (2012) 68 World's Poultry Sci. J. 768, at 773.

${ }^{50}$ Zuidhof et al., id., pp. 2980-1 (cost of feed is about two thirds of cost of producing chicken meat).

${ }^{51}$ Robins and Phillips, op. cit., n. 49, p. 352 (references omitted).

52 id.

${ }^{53}$ R. Harrison, Animal Machines: The New Factory Farming Industry (1964).

${ }^{54}$ D. Fraser, 'Understanding Animal Welfare' (2008) 50(S1) Acta Veterinaria Scandinavica 1.
} 
(1) Basic health and functioning of animals, especially freedom from disease and injury ("health");

(2) “Affective states" of animals, like pain, distress and pleasure; and

(3) The ability of animals to carry out natural behaviour and have natural elements in their environment ("natural behaviours").

Defenders of animal welfare in large scale intensive agricultural animal production often focus on the first category and suggest that greater and more efficient production is consistent with animal welfare since unhealthy animals will not produce efficiently. ${ }^{55}$ Critics of intense agriculture, however, argue that this "productivist" perspective favours an unduly narrow conception of animal welfare that focuses on physical health as measured by observable disease or injury, without sufficient recognition of the sentience and therefore affective suffering of animals, and the impact on both health and affective states of the denial of the opportunity to engage in natural behaviour. ${ }^{56}$

At any rate there is ample evidence that intense industrial farming of meat chickens often leads to both significant basic health problems and affective suffering. ${ }^{57}$ Selective breeding of meat chickens leads to rapid growth rates and a radically altered posture ${ }^{58}$ which can predispose birds to both heart and leg problems. ${ }^{59}$ Leg problems can cause a lack of willingness and capacity to walk, scratch and perch. ${ }^{60}$ Heart problems can cause pulmonary hypertension and sudden death. High stocking densities, large flock sizes, and indoor confinement predispose birds to contact dermatitis (foot burn, hock burn and breast blisters) which can be very painful. ${ }^{61}$ Although improvements in health have been made via more sophisticated selections in breeding, ${ }^{62}$ there is debate in the literature as to what degree breeding, good management (especially in relation to the litter) and technology can ameliorate or prevent problems or whether the high stocking densities required for large scale commercial production will always have a negative impact on health and affective states. ${ }^{63}$ The very nature of the commodification process of intensive farming is to push the chicken's body as far as it can go to produce as

\footnotetext{
${ }^{55}$ See, for example, J.L. Barnett and P.H. Hemsworth, 'Welfare Monitoring Schemes: Using Research to Safeguard Welfare of Animals on the Farm' (2009) 12 J. of Applied Animal Welfare Sci. 114.

${ }^{56}$ See C.J.C. Phillips and J.C. Petherick, 'The Ethics of a Co-Regulatory Model for Farm Animal Welfare Research' (2015) 28 J. of Agricultural and Environmental Ethics 127.

${ }^{57}$ See Robins and Phillips, op. cit., n.49. See, also, Anonymous, 'Scientists' Assessment of Housing and Management on Animal Welfare' (2001) 4 J. of Applied Animal Welfare Sci. 3.

${ }^{58}$ Zuidhof et al., op. cit., n. 42, p. 2975.

${ }^{59}$ Anonymous, op. cit., n.57, p. 42.

${ }^{60}$ Robins and Phillips, op. cit., n. 49, pp. 355-6. See, also, G.S. Sanotra et al., 'Influence of Stocking Density on Tonic Immobility, Lameness and Tibial Dyschondroplasia in Broilers' (2001) 4 J. of Applied Animal Welfare Sci. 71, at 72; European Food Safety Authority (EFSA) Panel on Animal Health and Welfare, 'Scientific opinion on the influence of genetic parameters on the welfare and the resistance to stress of commercial broilers' (2010) 8 EFSA J. 1.

${ }^{61}$ Zuidhof et al., op. cit., n. 42; H.A. Elson, 'Poultry Welfare in Intensive and Extensive Production Systems' (2015) 71 World's Poultry Sci. J. 449, at 451. But note that Elson's review goes on to suggest that contact dermatitis is found in greater prevalence and severity among free range chickens than confined chickens: at 452 . See, also, P.J. Hepworth et al., 'Hock Burn: An Indicator of Broiler Flock Health' (2011) 168 Veterinary Record 303.

${ }^{62}$ See Elson et al., op. cit., n. 49, p. 773; Zuidhof et al., op. cit., n. 42, p. 2970.

${ }^{63}$ See S. Buijs et al., 'Stocking Density Effects on Broiler Welfare: Identifying Sensitive Ranges for Different Indicators' (2009) 88 Poultry Sci. 1536. Cf. M.S. Dawkins, C.A. Donnelly and T.A. Jones, 'Chicken Welfare Is Influenced More by Housing Conditions Than by Stocking Density’ (2004) 427 Nature 342. See, also, Robins and Phillips, op. cit., n. 49, p. 360.
} 
much meat as possible in the shortest time. The unstated assumption is that the animal only has to survive at sufficient health to reach slaughter weight. There is thus a constant tension between productivity and cost effectiveness, and the potential for a more healthy, happy life for the chickens. ${ }^{64}$

Moreover, it is not just the health and affective impacts of confinement in large scale shed systems that is at issue. It is also the opportunity to engage in natural behaviours. Chickens are highly sentient creatures with complex social hierarchies. They are capable of learning and also gain great enjoyment from behaviours such as pecking and ground scratching, as well as perching, dust bathing and nesting. ${ }^{65}$ Confinement at high stocking densities inside barns and in large flock sizes frustrates natural behaviours and social organization, leading to frustration and stress driven behaviour. ${ }^{66}$ Lower stocking density and group size within both barn systems and barn plus range systems may provide more opportunity for natural behaviours and less stress. Enrichment opportunities (such as perches and straw bales inside the house or a wellmanaged and vegetated outside range with trees or other structures) will also provide opportunities for natural behaviours such as perching, scratching, foraging, and dust bathing. These activities can also decrease anxiety, boredom and frustration and increase leg health. ${ }^{67}$

Some however argue that range access may lower welfare due to stress on open and bare ranges, since chickens prefer cover when outside and are fearful of predators, humans and sudden changes. ${ }^{68}$ Chicken meat industry advocates also suggest that free ranging can introduce health risks from contact with wild birds and soil born pathogens. ${ }^{69}$

Two broad issues have become the topics of contention in public policy debate around meat chicken welfare:

- how chicken's health can best be managed and suffering reduced within intensive large scale systems;

- whether and how chickens should be given opportunities to engage in natural behaviors via outside ranges attached to barns or outdoors based production systems.

As discussed in Part 3, the two main higher welfare label claims in Australia (RSPCA Approved and FREPA free range) address respectively the first and second issue above.

\section{Backwards Mapping the Food Label as Governance Space: Methodology and Data}

Parker has previously suggested the need for a methodology to "backwards map" the claims staked on food labels in order to broaden the governance gaze beyond the often narrow limits of consumer choice to the production and distribution practices behind the label. ${ }^{70}$ This methodology starts with what the consumer sees in the market - food labelling and marketing

\footnotetext{
${ }^{64}$ A. Butterworth, 'Cheap as Chicken' in The Meat Crisis: Developing More Sustainable Production and Consumption, eds. J. D’Silva and J. Webster (2010).

${ }^{65}$ See PoultryHub, 'Enriching the Range to Reduce Feather Pecking', at $<$ http://www.poultryhub.org/enrichingthe-range-to-reduce-feather-pecking/>. See, also, A. Potts, Chicken (2012) 31-52.

66 PoultryHub, id.

${ }^{67}$ See Robins and Phillips, op. cit., n. 49, p. 361.

${ }^{68}$ Anonymous, op. cit., n. 57, p. 38.

${ }^{69} \mathrm{See}$, for example, 'Barnaby Joyce correct on bird flu risk in free-range chicken farms' ABC Fact Check, 8 November 2013, at <http://www.abc.net.au/news/factcheck/2013-11-01/barnaby-joyce-bird-flu-free-rangechicken-farms/5043614>.

${ }^{70}$ Parker, op. cit., n. 1313 Cf R. F. Elmore, 'Backward Mapping: Implementation Research and Policy

Decisions’ (1979) 94 Political Sci. Quarterly 601.
} 
claims - and then traces back the networks of public and private governance efforts throughout the supply chain that create and support the claims on the label, and, finally, the underlying production practices themselves.

The first step is a "visual sociology"71 of the label in its retail context with particular attention to claims made explicitly (written or spoken) and implicitly (pictures, signs, symbols, context) about the ethical values instantiated in the product and visual appeals to regulatory support (eg credence claim accreditation logos). We examined the higher welfare claims that have emerged in the Australian market place via a product survey of whole roast chickens and fresh chicken meat (breasts, thigh fillets, and whole uncooked chicken) available for retail sale in a selection of 27 supermarkets (Coles, Woolworths, IGA and Aldi stores) and alternative retail outlets (smaller independent stores and farmers markets) in a variety of location around Melbourne between April and December 2015. Photos were taken of each product and its shelf display and a variety of data collected, including the price per $100 \mathrm{~g}$, claims made, accreditations, and the origin of processed products (where data were available). Supermarkets are the largest conduit for consumption of chicken in Australia with about 70 per cent of all chicken meat sold fresh for home cooking and the vast majority of that sold in supermarkets. ${ }^{72}$

The second step is to investigate each appeal to values and regulation on the label using critical supply chain analysis ${ }^{73}$ and regulatory network analysis. ${ }^{74}$ We therefore compared the various animal welfare claims identified on these products with information about the accreditation schemes and production practices behind them through desktop review of accreditation organisations' and producers' websites, and interviews with representatives of the organisations responsible for accreditation systems, the two major retailers, producers and farmers and animal welfare and consumer NGOs. A total of 17 interviews with stakeholders were conducted with each interview lasting around one hour, with informed consent, audiotaped (notes were taken where permission to audio-tape was not given). The aim here was to uncover the various formal and informal governance arrangements that support and stabilise relationships along the food chain and the representations made to the consumer, and how this chain (and its regulatory governance) has been contested and alternatives developed.

The third step in backwards mapping is to uncover how consumer choice has been constructed, and to inquire into the values and interests represented by the label as a governance space. This is done by comparing the stories on the labels with the food chains behind the labels, relevant networks of governance arrangements and the degree of conflict, change and stability in these chains and arrangements. Who bears the burdens and who the benefits of the various food chains and regulatory arrangements uncovered? What values and interest are represented by the regulatory options chosen? What regulatory options and associated values and interests have been sidelined or occluded? How have regulatory choices already made along the food chain created and constricted the possibilities that consumers have to choose products in a way that changes the moral economy of the value chain? In this case study the researchers prepared their own analysis and then a multi stakeholder workshop was also held to help understand issues. This understanding was also supplemented by a comprehensive analysis of newspaper articles and policy documents related to poultry chicken welfare regulation, civil society

\footnotetext{
${ }^{71}$ C. Richards, G. Lawrence \& D. Burch, 'Supermarkets and Agro-Industrial Foods' (2011) 14 Food, Culture and Society 29 at 38-39.

${ }^{72}$ Australian Chicken Meat Federation (ACMF), The Australian Chicken Meat Industry: An Industry in Profile (2011) 3.

${ }^{73}$ Dixon, op. cit., n. 25; Guthman, op. cit., n. 35.

${ }^{74}$ See Eberlein et al, op. cit., n. 12.
} 
campaigns and market initiatives over the last twenty-five years in order to ensure the broader trends were captured. The results of this latter data collection have been reported in more depth elsewhere. ${ }^{75}$

The desk top review and interviews were coded and analysed using a grounded theorizing approach (in which themes are developed from a close reading of the data rather than hypotheses tested on the data) in order to understand why and how different accreditation systems were introduced and how the various actors in the regulatory network interacted with each other. As some of the interviews and the multi-stakeholder workshop were undertaken "off the record" in order to secure participation in discussion of controversial issues, publicly available sources, rather than direct interview quotations, are used wherever possible in this paper.

\section{EVALUATING HIGHER WELFARE LABELLING}

\section{The Emergence of Higher Welfare Labelled Chicken in Australia}

Our review of policy documents and newspaper articles shows that since about 2000, concern about the overcrowding of meat chickens inside large barns has been a topic of frequent public discussion, civil society contestation and industry action in Australia. ${ }^{76}$ The absence of government commitment to enacting and enforcing higher standards of animal welfare to address these issues has prompted industry and retailer innovation in higher animal welfare labelling to address public concern and civil society contestation. Figure 1 summarizes key policy and market developments over that time frame. The top half of the diagram shows official government policy decisions and regulatory actions. The bottom half shows the development of private labelling initiatives and civil society activism. These are an interacting set of provocations and alliances - which have created and shaped the label claims we now see in the market within the broader context of the relentless rise in chicken meat production and consumption described above.

\section{[Figure 1 about here]}

The primary government regulatory instrument affecting broiler chicken welfare in Australia is the Commonwealth Model Code of Practice: Domestic Poultry ("the Poultry Code"). ${ }^{77}$ It is widely seen as inadequate by animal advocacy groups because it allows high stocking densities and does not restrict flock size nor mandate outdoor access or any enrichment opportunities in or outside the shed thus failing to address consumer and animal advocate concerns with chickens' affective suffering and opportunities to engage in natural behaviours. ${ }^{78}$ Moreover

\footnotetext{
${ }^{75}$ Not reported in detail in this paper. See C. Parker, R. Carey and G. Scrinis, 'The Consumer Labelling Turn in Farmed Animal Welfare Politics: From the Margins of Animal Advocacy to Mainstream Supermarket Shelves' in Alternative Food Politics: From the Margins to the Mainstream, eds. M. Phillipov and K. Kirkwood (2018). 76 id.

${ }^{77}$ Primary Industries Standing Committee, Australian Model Code of Practice for the welfare of animals domestic poultry - $4^{\text {th }}$ Edition - SCARM Report 83 (2002).

${ }^{78}$ See J. Goodfellow, 'Regulatory Capture and the Welfare of Farm Animals in Australia' in Animal Law and Welfare - International Perspectives, eds. D. Cao and S. White (2016); K. Sharman, 'Farm Animals and Welfare Law: An Unhappy Union' in Animal Law in Australasia: A New Dialogue, eds. P. Sankoff and S. White (2009).
} 
the monitoring and enforcement of compliance with the Poultry Code has been widely criticised as lacking and ineffective for two reasons by animal advocates, regulatory scholars and recently an independent government review of agricultural regulation because (1) it is the responsibility of state and territory departments of primary industries which lack independence from industry, it is criticised for being subject to regulatory capture; and (2) both federal and states governments have not provided adequate resourcing for regular monitoring and enforcement. ${ }^{79}$

Farm animal advocacy group Voiceless published the first comprehensive, policy oriented expose of Australian meat chicken welfare and its regulation in $2008{ }^{80}$ It criticized Australian governments for failing to follow the lead of the $2007 \mathrm{EU}$ directive on meat chicken welfare that set a new international benchmark for chicken welfare standards. ${ }^{81}$ It also challenged Australian supermarkets and consumers to follow the example of the United Kingdom in radically increasing the consumption of higher welfare labelled chicken meat.

"Organic" and "free range" labelled chicken meat had been available in Australia from at least the mid-1990s. ${ }^{82}$ In 2011 however the two dominant Australian supermarkets made the creation and advertising of higher animal welfare labelled products a prominent part of their brand identity. ${ }^{83}$ Massive media coverage about cruel treatment of Australian cattle and sheep exported live on board ships to Asia and the Middle East had prompted wide public concern about Australian agricultural animal welfare standards in 2011. ${ }^{84}$ A slow and weak government response to the scandal ${ }^{85}$ created the opportunity for the two dominant supermarkets to step into the governance gap and give themselves a "halo effect" through their own action on animal welfare standards. The threatening arrival in Australia of European and US own brand supermarkets, Aldi, LIDL and Costco had also made it urgent for the Australian incumbents to find new marketing strategies to defend their customer base. ${ }^{86}$

At the same time repeated campaigns by consumer advocates, animal advocates and Greens (Australia's third political party) to introduce legislated higher welfare labelling reforms were failing. ${ }^{87}$ A 2011 government review found that higher welfare labelling was a "consumer values" issue that did not warrant mandatory food labelling standards. Instead industry selfregulation with back up consumer protection enforcement against misleading conduct should

\footnotetext{
${ }^{79}$ Goodfellow, op. cit., n. 78; Productivity Commission, Regulation of Australian Agriculture (2016).

${ }^{80}$ K. Sharman and S. Kossew, From Nest to Nugget: An Exposé of Australia's Chicken Factories (2008).

${ }^{81}$ Council Directive 2007/43/EC laying down minimum rules for the protection of chickens kept for meat production [2007] OJ L182/19.

${ }^{82}$ See, for example, N. Blavier, 'Chicken Feed' Sydney Morning Herald, 12 April 1994.

${ }^{83}$ Coles, 'News: RSPCA Approved to hit shelves in Victoria, South Australia and Tasmania for the first time' (April 2011) (archived with first author); Woolworths Limited, Corporate Responsibility Report 2013 (2013) 23, at <https://www.woolworthsgroup.com.au/icms_docs/186061_corporate-responsibility-report-2013.pdf>. See, also, C. Parker and G. Scrinis, 'Out of the Cage and into the Barn: Supermarket Power, Food System Governance and the Regulation of Free Range Eggs' (2014) 23 Griffith Law Rev. 318; T. Lewis and A. Huber, 'A Revolution in an Eggcup? Supermarket Wars, Celebrity Chefs and Ethical Consumption' (2015) 18 Food, Culture \& Society 289.

${ }^{84}$ See C.M. Tiplady, D.B. Walsh and C.J.C. Phillips, 'Public Response to Media Coverage of Animal Cruelty' (2013) 26 J. of Agricultural and Environmental Ethics 869.

${ }^{85}$ See Chen, op. cit., n. 17, pp. 91-5.

${ }^{86}$ See G. Mortimer, 'Woolies private label strategy will play directly into the hands of Aldi' The Conversation, 30 March 2016, at <http://theconversation.com/woolies-private-label-strategy-will-play-directly-into-the-handsof-aldi-56914>.

${ }^{87}$ For example, the Greens' Truth in Labelling (Free-range Eggs) Bill 2011 (NSW) lapsed in 2013.
} 
be sufficient. ${ }^{88}$ In Europe by contrast higher welfare terms for chicken meat are legislatively defined. ${ }^{89}$

Also in 2011 Australia's powerful national consumer protection regulator, the Australian Competition and Consumer Commission (ACCC) commenced enforcement action for misleading conduct against industry body the Australian Meat Chicken Federation (ACMF) and three major chicken meat producers for claiming that meat chickens grown conventionally in cramped conditions inside barns with no outdoors access were "free to roam". The consumer action was prompted by a complaint and lobbying from the Barristers Animal Welfare Panel working with Animals Australia (one of Australia's most prominent animal advocacy organization). The action garnered much media attention, ${ }^{90}$ and by 2013 the ACCC had succeeded against all parties in court. ${ }^{91}$ Simultaneously public concern about the definition of "free range" eggs erupted on the grounds that supposedly "free range" birds were not kept in a system where most hens went outside on most days but were largely confined in crowded conditions in barns and given only theoretical access to outdoor ranges. This too attracted successful ACCC action. ${ }^{92}$ In 2012 the chicken meat industry withdrew a proposal it had made to introduce an industry accredited "free range" certification standard. ${ }^{93}$ This left the governance space free for the supermarkets to determine their own higher welfare standards.

By 2014, Coles and Woolworths had both implemented "RSPCA Approved" certification labelling for all own brand chicken meat sold in store, representing the vast majority (63 per cent) of fresh chicken meat now sold. ${ }^{94}$ Coles and Woolworths also now offer FREPA (Free Range Egg and Poultry Australia) accredited "free range" and ACO (Australian Certified Organic) accredited chicken as premium branded products, representing about 20 per cent of the market. ${ }^{95}$ Table 2 summarises the situation.

\section{[Table 2 about here]}

Table 3 summarises the meaning of the two most significant higher welfare label certifications - RSPCA Approved and FREPA Free Range - and compares them with the Model Code of Practice (ie the regulatory standard), the niche Australian Certified Organic and the EU legally

\footnotetext{
${ }^{88}$ Independent Expert Panel for the Review of Food Labelling Law and Policy, Labelling Logic: Review of Food Labelling Law and Policy (2011) 7, 12 (Recommendations 2, 37 and 38).

${ }^{89}$ Commission Regulation (EC) No. 543/2008 laying down detailed rules for the application of Council Regulation (EC) No. 1234/2007 as regards the marketing standards of poultry meat [2008] OJ L157/46.

${ }^{90}$ See ACCC, 'ACCC Takes Action Over "Free to Roam" Chicken Claims' (7 September 2011), at $<$ https://www.accc.gov.au/media-release/accc-takes-action-over-free-to-roam-chicken-claims >.

${ }^{91}$ Australian Competition and Consumer Commission v. Turi Foods Pty Ltd (No. 2) [2012] FCA 19; Australian Competition and Consumer Commission v. Turi Foods Pty Ltd (No. 4) [2013] FCA 665.

${ }^{92}$ C. Parker and J. de Costa, 'Misleading the Ethical Consumer: The Regulation of Free-Range Egg Labelling' (2016) 39 Melbourne University Law Rev. 895, at 910-12.

93 ACCC, 'Australian Poultry Industry Assoc. CTM 2012', at $<$ https://www.accc.gov.au/about-us/consultationssubmissions/public-consultations/australian-poultry-industry-assoc-ctm-2012>.

${ }^{94}$ RSPCA, RSPCA Approved Farming Scheme: Impact Report 2016 (2016), at $<$ https://rspca.org.au/sites/default/files/2016-10-RSPCA-AFS-Impact-Report-web.pdf>.

95 ACMF, op. cit., n. 72.
} 
mandated definition of "free range" (for comparison). The following sections evaluate the impact of these two standards.

\section{[Table 3 about here]}

\section{Evaluation of RSPCA Approved}

(a) Does RSPCA Approved accurately inform consumers?

The RSPCA describes RSPCA Approved as aimed at "establishing animal welfare standards that go beyond regulatory requirements and that are commercially viable," "enabling differentiation and marketing of products", and "offering consumers ... a higher welfare alternative". ${ }^{96}$ It accepts that large scale, intense, animal farming will continue and seeks to ameliorate the welfare of the animals involved. This is in contrast to the position of Australia's two most prominent animal advocacy groups, Voiceless and Animals Australia, which both actively seek to abolish factory farming and promote alternative free range farming, reduced animal food consumption and veganism. ${ }^{97}$ RSPCA Approved is advertised as "better welfare" and "raised better, tastes better" by Coles ${ }^{98}$ and by the RSPCA as "providing a better life for farm animals". 99

The RSPCA Approved governance system does generally provide higher welfare within the intense industrial system than does government regulation and conventional industry practice. But it is an incremental rather than a transformative improvement. It does not substantially alter the model of intense industrial farming, but rather makes minor but important improvements on the Model Code requirements (see Table 3). For example, RSPCA Approved has strict requirements about keeping litter dry, requires some minimal but important enrichment opportunities inside barns (perches and hay bales), and also requires lower stocking densities than the Model Code (allowing more space for the birds). It does not require outdoor access and the RSPCA does not see "free range" as a guarantee of good welfare.

Growers have had to adopt some new management practices (lower stocking densities, greater attention to litter management) but they have not had to adopt new technology (for example, the barns are the same, as are the litter, the tractors, and the breeding of the birds) nor make more permanent changes to their "techno-ethics". ${ }^{100}$ Similarly the "margin for care" has not increased. That is RSPCA Approved products do not appear to have a higher economic margin than conventional products. ${ }^{101}$ Nor do they seem to conceptually reframe production to prioritise care of animals over efficiency of production. Coles' advertising of its RSPCA Approved chicken as better welfare "at no extra cost to you", highlights this point, and there is very little or no difference in price between RSPCA Approved and non RSPCA Approved

\footnotetext{
96 RSPCA, Approved Farming Scheme: Impact Report 2014 (2014) 5.

${ }^{97}$ RSPCA has sometimes been criticised for this approach by other animal advocacy groups: Chen, op. cit., n. 17, p. 183.

${ }^{98}$ Photographs of instore advertising and labels are on file with the authors and available from $<$ http://fvas.unimelb.edu.au/research/projects/regulating-food-labels-the-case-of-free-range-food-products-inaustralia/about>.

${ }^{99}$ RSPCA, op. cit., n. 96.

${ }^{100}$ Miele and Evans, op. cit., n. 14.

${ }^{101}$ Butterworth, op. cit., n. 64, pp. 137-8.
} 
conventional chicken meat. Interviews and newspaper article analysis suggest the main potential cost impact is the lower stocking density (meaning more sheds required for the same number of chickens). ${ }^{102}$

No images or pictures suggested the animals were outside. The Coles advertising shows a barn in the sunset and Woolworths images are suggestive of a wooden barn. Nor does any advertising claim a substantially different method of farming is used - only a more humane version of conventional farming.

Under RSPCA Approved certification, monitoring of farms is more proactive than government regulation, meaning that the standards are more likely to be implemented in practice (see Table $3)$. The process by which the RSPCA Approved requirements are created also represents some improvement on the more industry dominated government standards making process. They are based on independent (non industry funded) animal welfare science and animal welfare advocacy as well as consultation with industry and supermarkets. They are reviewed regularly and therefore provide an opportunity for continuous improvement. The adoption of RSPCA Approved by the supermarkets in effect ensures that basic government standards are monitored, enforced and incrementally improved for those chickens, whereas current government regulation is poorly monitored and enforced.

The RSPCA provides much information about what its standards do and do not mean, and the label claims themselves do not make inaccurate statements. Nevertheless the "RSPCA Approved" stamp may give the impression that an absolute standard of humane care of animals has been achieved (that is, chickens have been treated humanely) rather than a relative standard (that is, chickens have been treated more humanely than government regulation requires). As one animal advocate put it,

RSPCA do provide a few bales of hay and whatever. But that's, well, better than nothing. I don't think it really changes things very greatly. It might give some of them something to do on occasions... I do understand that that's pulled back on the most extreme densities and such things in the industry. But I think I see it as a missed opportunity to actually move them to a really much better standard. ${ }^{103}$ (underlining added)

(b) Does RSPCA Approved Change Practice and Governance?

The dominance of RSPCA Approved in the current retail market for chicken meat is dependent on an alliance between the supermarkets (who have adopted it as the baseline animal welfare standard for own brand chicken), the RSPCA (Australia's most highly respected civil society organisation and a fairly mainstream animal welfare organization ${ }^{104}$ ), and chicken producers (notably mid-tier producer, Hazeldenes who worked with Coles in the first instance to trial and adopt the RSPCA Approved standard, with the two largest producers coming on board soon after). This has impacted a large swathe of the market in a small way: official figures suggest that the vast majority (63 per cent) of fresh chicken meat sold is now RSPCA Approved. Indeed, producer interviewees told us that some of the major producers are now finding it easier to make all chicken production RSPCA Approved rather than operate different systems with different growers for different retailers and fast food companies. Moreover (as suggested above) RSPCA Approved is better monitored and enforced (through regular auditing visits and

\footnotetext{
${ }^{102}$ L. Poole, 'Chicken meat meets RSPCA approval' ABC Rural, 9 May 2011, at <http://www.abc.net.au/sitearchive/rural/content/2011/s3211712.htm>.

103 Anonymous interviewee O7, Melbourne, Australia, 23 October 2015.

${ }^{104}$ Chen, op. cit., n. 17, p. 167.
} 
the threat of loss of contracts) than the more minimal government standards. This suggests that most chickens grown for meat in Australia have benefited from RSPCA Approved in a small way.

The market has thus accommodated itself to increased demands for animal welfare via a combination of incremental improvement and the two supermarkets' co-optation of the "halo effect" from an animal welfare organization. Chen's systematic study of animal welfare politics and policy in Australia suggests that the relationship between RSPCA Approved and the supermarkets represents "an exchange that creates a degree of mutual capture". ${ }^{105}$ This mutual exchange is however a "fragile construction". ${ }^{106}$ It is vulnerable to marketing and brand identity changes on the supermarket side. As one chicken industry interviewee commented, RSPCA Approved has the makings of becoming a non-negotiable industry standard but it is not there yet:

I'd like to see people stop competing on animal welfare; just as they have pretty much agreed not to have food safety be a competitive issue. So they don't say my product is safer than your product. I would like them to move away from animal welfare as a marketing differentiating point, so there's higher welfare and higher higher welfare and there's highest welfare and you know there's no end to it. So I think maybe the RSPCA becoming very well known, widely accepted... I think that that's good for us all if we would just all do RSPCA and then move on with something else, you know differentiate your flavour and quality and whatever else...

The RSPCA at first sight appears to be the dominant regulatory actor "orchestrating" a market change through forging an alliance with the supermarkets. However, it is the RSPCA who needs the supermarkets to get access to and traction over producers, more than the supermarkets need the RSPCA "halo". This is most evident by the fact that to date Australian supermarkets do not require the RSPCA certification for the other higher welfare animal products they sell (free range eggs and sow stall free pork products). The alliance between the RSPCA and the supermarkets is therefore vulnerable if the supermarkets decide that priority for animal welfare or an alliance with the RSPCA itself no longer fits their branding strategies, or if producers and supermarkets decide the cost of compliance does not warrant the competitive advantage achieved. As another industry interviewee pointed out, this appears to have occurred in the United Kingdom with the decline of RSPCA Freedom Foods:

I believe [RSPCA Freedom Foods in the United Kingdom] got to within about 80 per cent of the total production. Everybody was achieving the standard. Now it's completely declined and people [producers] have moved away from it, because it gets to the point where people just look at it and go, this is costing me far too much money to achieve this; it's not costeffective and not productive, so we can't sustain it.

RSPCA Approved is also vulnerable to the possibility consumers will come to see RSPCA Approved as delivering less substantive change than it promises. Other animal welfare advocates may indeed contest RSPCA Approved as being of not a high enough standard or even "welfare washing". At the time of writing an animal advocacy group had orchestrated just such a campaign against an RSPCA Approved meat chicken farm in Western Australia.

\section{FREPA Free Range}

\footnotetext{
105 id., p. 200.

${ }^{106}$ Miele and Lever, op. cit., n. 4, p. 70.
} 
A European meta-analysis of consumer preference studies indicates that "outdoor access" is always high preference among consumers seeking higher welfare animal food products. ${ }^{107}$ "Free range" label claims particularly appeal to the idea that birds should have the opportunity to engage in natural behaviours by going outside, and some boutique or micro free range farms emphasise small flock sizes and agro ecological farming methods that give chickens ample opportunity to forage, peck, scratch and dust bathe. This paper focuses however on the dominant free range label claim, FREPA free range accredited.

(a) Does FREPA free range accurately inform consumers?

In addition to the use of the term "free range", the labelling images on the FREPA free range accredited meat chicken in Coles and Woolworths emphasize the outdoors with green hills and pasture, although often lacking actual chickens in the landscape. Most "free range" chicken meat available on the market has not come from birds that spent their days foraging, pecking and dust bathing in pastured fields. Indeed, the very characteristics of intense industrial meat chicken production discourage ranging in a variety of ways, even if access to a range is provided and FREPA free range does not create a different system.

The publicly available FREPA standard is very minimal with only a few broad guidelines and little specification of issues such as indoor stocking density and amount of popholes per shed (see Table 3). A FREPA spokesperson told us that there is more detail in the commercial-inconfidence audit guidelines that support the standard, but we were not able to see these. It is clear that FREPA is geared towards a large-scale barn-based system that provide chickens with access to a range rather than an outdoors based free range system. The dominant free range brand, Lilydale, stocked in Coles is FREPA accredited but adds to the FREPA Accreditation on the labelling with the much more prominent "Lilydale promise" that includes additional dot point information about the living conditions of the chickens: "Access to outdoors; perching bales; huts for shade; nutritious feed." It also includes the statement emphasizing its overreach of the free range certification standard:

Lilydale chickens, once fully feathered, are free to access the outdoor range area from sunrise to sunset. With bales and wooden ramps for perching, shade huts to protect them from the sun and tree planting programs in every pasture, at Lilydale we don't just meet free range standards, we better them. (underlining added)

The key feature of accredited "free range" chicken in Australia is access of chickens to the range from the age of 21 days (three weeks) onwards, but this represents only about half of their short lives. Once they do gain access to the range, as a number of both industry and animal advocate interviewees put it, the birds are free to range rather than every bird actually free ranging every day:

"Free range" or "free to range"? That's where it gets cloudy. If the consumer is thinking that if they buy a free range chicken that that chicken was outside on the range, then there's no guarantees that that particular chicken went outside on the range. But what is important is that that chicken has got access to get onto the range if it chooses to do so. (free range industry spokesperson)

To me if the birds are provided with access is that what people expect? Or do they expect that the bird that they eat has been outside, has actually gone outside? Do they expect that

\footnotetext{
${ }^{107}$ M. Janssen, M. Rödiger and U. Hamm, 'Labels for Animal Husbandry Systems Meet Consumer Preferences: Results From a Meta-Analysis of Consumer Studies' (2016) 29 J. of Agricultural and Environmental Ethics 1071.
} 
the birds have spent a significant amount of time outside? I don't really know. I can't answer that... I mean you don't want to be forcing birds to go outside if they don't want to go outside. (industry spokesperson)

Even at slaughter meat chickens are still little more than overgrown chicks and may not be fully feathered and behaviourally ready to range. ${ }^{108}$ Moreover by the time they are ready to range, they may be too large and not accustomed enough to exercise to be capable of, and motivated to, range. ${ }^{109}$ Industry interviewees reported that actual ranging behaviour depends on access to popholes, scale and size of sheds and flocks, the weather, and whether there is any enrichment, shade and other features of the range to entice them outside, as well as the breeding of the bird. In relation to the latter one micro free range farmer reported that he had tried to stock a free range farm with conventionally bred chickens and found they simply would not range:

What we found in the trees here is that all they would do is sit beside their feed bin, they wouldn't forage, largely because they couldn't. They were so heavy and overburdened with muscle and breast tissue, wouldn't forage and just very lethargic, not bred.

This free range farmer had some difficulty sourcing a different breed of chicken that would be capable of ranging. As interviews with industry representatives made clear, the very idea of free ranging conflicts with the ethos and technologies of intense industrial farming because it lessens the grower's control of the system, of the activity of the birds, their growth and even their mortality - thus impacting on profits. Contemporary tunnel ventilated shed systems allow the grower to control the temperature and atmosphere (in order to address health and suffering associated with cold or heat and encouraging rapid growth) are designed to be kept shut. When the sides are opened up for free ranging in hot, cold or damp weather, they do not work as designed, creating a disincentive for the farmers to encourage free ranging. Indoor factory farming was introduced in order to precisely control the environment in the interests of the health and productivity of the chicken. A number of interviewees pointed out that free ranging makes this more difficult and increases the mortality rate. The added exercise also impacts on economic productivity - free range chickens eat more feed and reach slaughter weight later.

(b) Does FREPA Free Range Change Practice and Governance?

FREPA free range only represents 15 per cent of the market and as such does not represent a systemic change in quantitative terms. Our interviews suggested that the common industry view is that free range is a luxury that people will buy if they have the money to do so, a higher price choice for those consumers who consider welfare and taste important, rather than a message to producers and regulators to improve standards across the board. It is a market niche - a way to gain a higher price for a differently marketed product ${ }^{110}$ - and not currently a serious challenge to prevailing industry practice.

The dominance of RSPCA Approved means that free range meat chicken is not under serious scrutiny by consumer groups and is therefore less likely to be challenged via consumer protection enforcement or civil society activism. Indeed, the minimal incremental systemic change wrought by RSPCA Approved may preempt potential for further innovation in free range. One industry interviewee suggested that there was an indication that consumers are "now accepting RSPCA and not choosing free range. It ticks the box. I'm doing the right thing.

\footnotetext{
${ }^{108}$ Anonymous, op. cit., n. 57, p. 37.

109 id., p. 41.

${ }^{110}$ Bartley et al., op. cit., n. 15, p. 114-15.
} 
I'm doing the ethical chicken and they're increasingly less interested in paying a premium or free range if they can get RSPCA."

Moreover the "free range" claim is largely meaningless since meat chickens have little opportunity or capacity to free range during their short lives. Quite significant innovation in technology, management, and indeed governance, of meat chicken production would be necessary to create a commercially viable free range system. There is some ongoing experimentation in this direction by various micro free range producers and alternative small scale pasture based accreditations. ${ }^{111}$ Interviewees informed us that there are however barriers to entry for innovators in meat chicken production, that are beyond the scope of this paper to explore in detail but include access to abbatoirs, access to suitable technology and feed, access to retail outlets, consumer understanding of the issues, and whole of government commitment to a more sustainable and healthy food system overall. The dominance of the conventional intense industrial barn-based system, and its successful legitimation via the supermarkets and RSPCA Approved, may further serve to "lock in" an approach that at best ameliorates the health and suffering of chickens in minor ways but does not change the system.

\section{CONCLUSION}

Animal welfare issues for meat chickens have been created by extreme breeding and the intense "mono-culturing" of single animal species in controlled conditions. These are also the very conditions that have created an abundance of affordable meat. Our analysis suggests that labelling can be an important mechanism by which an "overflow" of civic concern about animal welfare is expressed and managed. Political consumerism has some traction, but it is quite limited.

In Australia RSPCA Approved and FREPA free range are two different ways in which higher welfare labelling has impacted, in a limited way, on chicken welfare. We have shown that RSPCA Approved provides a small incremental improvement in welfare for the vast majority of Australia's meat chicken population. Yet it also helps legitimate or (to coin a term) "welfare wash" the overall project of intense animal industry through the "halo effect" of prominent "RSPCA Approved" stamps on supermarket products. FREPA free range labelling by contrast is used to market a niche product. It is selling ethical comfort to those who can afford to pay, yet it only marginally improves the lives of a small proportion of chickens.

This does not mean that labelling initiatives have no impact. The existence of "free range" and other higher welfare label claims also provides an ongoing (but not yet realized) source of challenge and disruption to intensive barn-based production. As some producers experiment with more truly alternative methods of farming meat chickens, these may attract consumer and animal welfare interest. This may prompt change via the creation of new regulatory actors (for example new standards accreditation bodies), the forging of new alliances (for example between a supermarket or producer and an animal welfare organization) or legal action that stops one practice and/or mandates another (for example enforcement action against misleading or deceptive conduct). As long as social movement activism and farmer innovation keep occurring, there is the potential for improvement. The danger is that widespread adoption of an

\footnotetext{
${ }^{111}$ PROOF (Pasture Raised on Open Fields), at <https://www.proof.net.au/>, and the older Humane Choice, at $<$ http://www.humanechoice.com.au/>.
} 
incremental change (RSPCA Approved) may act as a stop on further productive tension and innovation.

Our analysis highlights the significance of the network of actors behind higher welfare labels. The label has become a space for contestation over the regulation and governance of the food production and retail process itself. The supermarkets have become particularly important intermediaries of the label as a governance space. Private accreditation standards (RSPCA or FREPA) are required or taken up only to the extent that other actors require them or influence them in some way, and it is Australia's two major supermarkets working together with the RSPCA and some processors that have largely cornered the field for higher welfare labelling of meat chicken. The chickens themselves may have benefitted (at least to a small degree) and this also represents an advocacy victory for the RSPCA. These are however fragile accomplishments in the sense that they depend on supermarkets to see RSPCA Approved as an important part of their brand identity. RSPCA Approved could have a more long-term impact on chickens' lives if producers, supermarkets and animal welfare groups were willing to cooperate to ensure that the incrementally improved standards in RSPCA Approved were adopted and, importantly, actively implemented and enforced by government as the new baseline regulation. In other industries and at other times, producers have sometimes advocated for standards to be improved to ensure a level playing field when some have voluntarily adopted higher public interest standards while others are still operating below industry standard. RSPCA Approved could, in theory at least, provide a leading-edge practice that can build capacity and acquiescence to improved government standards in the future.

Government action and inaction is still an important part of the animal welfare governance story. The combination of relatively low government mandated animal welfare standards, weak monitoring and enforcement of those standards and lack of legislative definitions for terms like "free range" have created an opportunity for retailer led higher welfare standards. But powerful action from another official government agency, the national consumer protection authority influenced which standards were taken up and which lost market share. In this case producer led standards lost legitimacy when the ACCC successfully prosecuted them as misleading in court. This left the governance space free for the supermarkets to become the most influential players. It also expanded the range of actors who have a real stake in and influence over the supply chain to include animal advocacy groups, alternative farming certifiers (organic and FREPA) and consumer advocates as well as the supermarkets. These actors all gained influence in addition to and sometimes at the expense of the growers, vertically integrated processors (or brands), industry associations, and government departments of primary industries.

We also see some hints that labelling aimed at political consumerism can be a mechanism for fomenting further "overflow" that might prompt further change in the market and even in official regulatory policy. ${ }^{112}$ The creation and propagation of new ideas, terms and images for production and marketing purposes may garner public support and translate into policy discourses. For example, animal products that show real life pictures of animals on vegetated ranges with shelter and enrichment can prompt citizens to ask why regulatory standards for free range chickens do not set out standards for shelter and enrichment on the range. They may also reinforce a growing majority view in western countries that animals are sentient beings whose interests should be considered in policy making. ${ }^{113}$ The creation of a new marketing term, such as "pastured", may help galvanise critique of inadequate free range production

\footnotetext{
${ }^{112}$ See A. Hutchens, Changing Big Business: The Globalisation of the Fair Trade Movement (2009).

${ }^{113}$ See G. Teubner, 'Rights of Non-Humans? Electronic Agents and Animals as New Actors in Politics and Law' (2006) 33 J. of Law and Society 497.
} 
methods. Even the visibility of RSPCA Approved in the supermarket aisle may help the RSPCA build public support for the idea it should have a more substantial role in monitoring the welfare of agricultural animals. The ongoing creation of new marketing terms and supporting certifications to take advantage of niche markets or to cement brand loyalty to particular retailers can help create technological and discursive resources that may become a prompt for better, more sustainable animal welfare practices and regulatory governance in the future. These are possibilities for further research and activism to test. 
Figure 1: Key developments in meat chicken welfare and labelling governance: 20022016

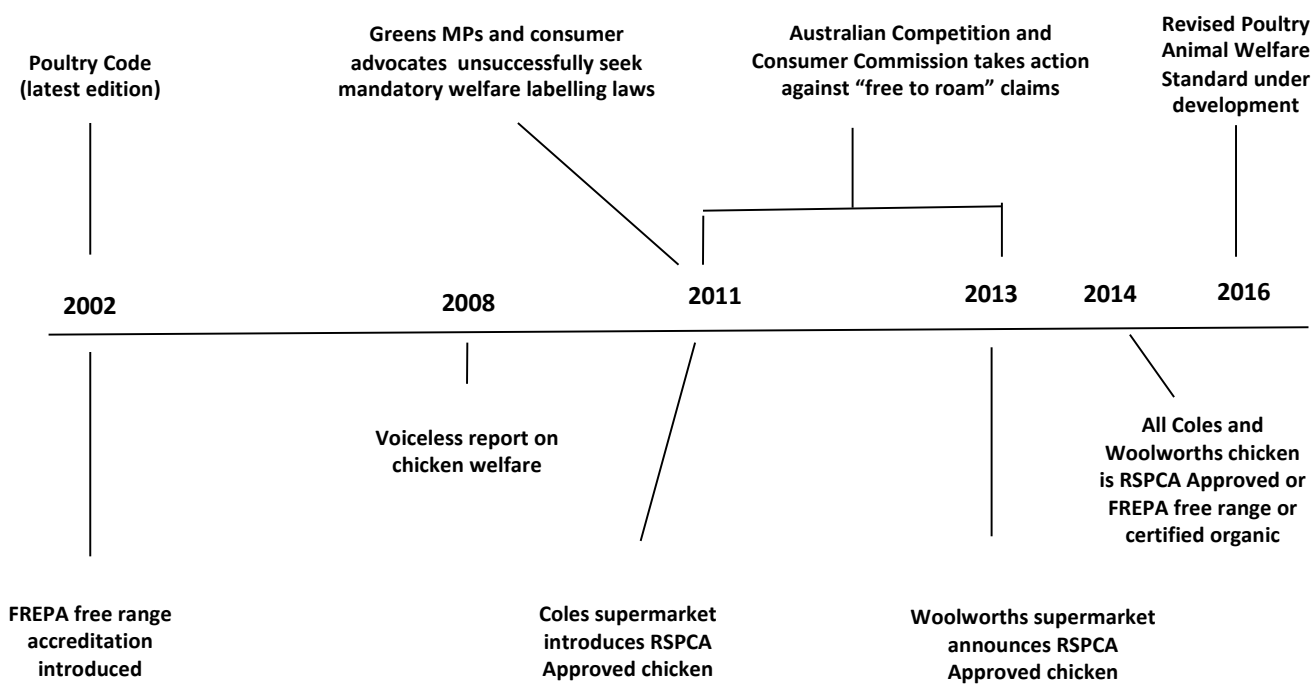


Table 2: Summary of impact of major higher welfare labels on market for fresh chicken meat and production practices

\begin{tabular}{|l|l|l|}
\hline Logo & Market share & Production System \\
\hline RSPCA Approved & $\begin{array}{l}\text { Dominant at both major } \\
\text { supermarkets - about 60\% }\end{array}$ & $\begin{array}{l}\text { Conventional intense industrial barn-based production system } \\
\text { with minor improvements for health and affective states of } \\
\text { chickens. }\end{array}$ \\
\hline FREPA Free Range & Premium product - about 15\% & $\begin{array}{l}\text { Conventional intense industrial barn-based production system } \\
\text { with outdoor access. }\end{array}$ \\
\hline $\begin{array}{l}\text { ACO Certified } \\
\text { Organic }\end{array}$ & Premium product - about 5\% & $\begin{array}{l}\text { Certifies both conventional systems with outdoor access and } \\
\text { alternative systems - standards require range management to } \\
\text { encourage actual ranging. }\end{array}$ \\
\hline
\end{tabular}


Table 3: Comparison of Model Code requirements with major private higher welfare accreditations (at January 2017)

\begin{tabular}{|c|c|c|c|c|c|}
\hline & $\begin{array}{c}\text { Government } \\
\text { Regulation } \\
\text { (Model Code) } \\
\end{array}$ & RSPCA Approved & FREPA Free Range & $\begin{array}{c}\text { Australian Certified } \\
\text { Organic }\end{array}$ & $\begin{array}{l}\text { EU definition of } \\
\text { "free range" }\end{array}$ \\
\hline Accreditation body & NA & $\begin{array}{c}\text { Highly respected } \\
\text { animal welfare agency }\end{array}$ & $\begin{array}{l}\text { Free range farmers } \\
\text { industry body }\end{array}$ & $\begin{array}{l}\text { Organic producers industry } \\
\text { body }\end{array}$ & NA \\
\hline $\begin{array}{l}\text { Indoor stocking density } \\
\text { Birds per square metre* }\end{array}$ & 20 & 17 & 14 & 12 & 13 \\
\hline Access to outdoor area & Not required & Not required & Required & $\begin{array}{c}\text { Required } \\
\text { (majority of daylight } \\
\text { hours) }\end{array}$ & $\begin{array}{c}\text { Required } \\
\text { (Continuous daytime } \\
\text { access to open-air runs) }\end{array}$ \\
\hline $\begin{array}{c}\text { Outdoor stocking density } \\
\text { Birds per hectare }\end{array}$ & Not specified & $\begin{array}{c}\text { Approx. } 113,000 \\
\text { (Outdoor area must be } \\
1.5 \mathrm{x} \text { shed area) }\end{array}$ & Not specified & $\begin{array}{c}2500 \\
(4800 \text { if rotated })\end{array}$ & 10,000 \\
\hline Outdoor shade/range & $\begin{array}{c}\text { Ready access to shaded } \\
\text { areas }\end{array}$ & $\begin{array}{l}>8 \mathrm{~m}^{2} \text { shade per } 1000 \\
\text { birds }\end{array}$ & Not specified & $\begin{array}{l}\text { Range to be managed to } \\
\text { encourage birds outdoors }\end{array}$ & $\begin{array}{l}\text { Range mainly covered by } \\
\text { vegetation or other shade }\end{array}$ \\
\hline Age at slaughter & Minimum 35 days & 35-55 days & 35-55 days & Minimum 70 days & Not specified \\
\hline $\begin{array}{c}\text { Monitoring and auditing } \\
\text { visits }\end{array}$ & Unknown - infrequent & 2-4 times per year & 1 time per year & $\begin{array}{l}1 \text { announced audit per year } \\
\text { plus unannounced audits }\end{array}$ & Varies by country \\
\hline Enforcement & $\begin{array}{l}\text { Little enforcement - } \\
\text { court prosecutions only } \\
\text { in cases of extreme } \\
\text { cruelty }\end{array}$ & $\begin{array}{l}\text { Compliance is enforced } \\
\text { by supermarket supply } \\
\text { contract conditions. } \\
\text { Growers who do not } \\
\text { comply may lose their } \\
\text { contracts with the } \\
\text { producers who supply } \\
\text { to the supermarkets. }\end{array}$ & $\begin{array}{l}\text { Brand owners enforce } \\
\text { via contracts with } \\
\text { growers or run own } \\
\text { facilities. } \\
\text { Brand owners or growers } \\
\text { might lose accreditation } \\
\text { if not compliant. }\end{array}$ & $\begin{array}{l}\text { Brand owners enforce via } \\
\text { contracts with growers or } \\
\text { run own facilities. } \\
\text { Brand owners or growers } \\
\text { might lose accreditation if } \\
\text { not compliant. }\end{array}$ & $\begin{array}{c}\text { Varies by country - } \\
\text { labelling definition only }\end{array}$ \\
\hline
\end{tabular}

* Calculated on basis of $2 \mathrm{~kg}$ per bird slaughter weight for consistency since some standards specify $\mathrm{kg}$ and some number of birds. 